\title{
Metabolic effects of 3,5-Diiodo-L-Thyronine
}

\author{
Marco Giammanco ${ }^{1}$, Manfredi Marco Giammanco ${ }^{2}$, Gaetano Leto ${ }^{3}$, Herbert R. Marini ${ }^{4}$ \\ ${ }^{1}$ Department of Surgical, Oncological and Oral Sciences, University of Palermo; ${ }^{2}$ Department Department of Human \\ Pathology in Adulthood and Childhood "G. Barresi", Medical School University of Messina; ${ }^{3}$ Department of Maternal \\ and Child Health Promotion of Internal Medicine, University of Palermo; ${ }^{4}$ Department of Clinical and Experimental \\ Medicine, University of Messina, Italy
}

\author{
Correspondence: Marco Giammanco, Department of Surgical, \\ Oncological and Oral Sciences, University of Palermo, Via Liborio \\ Giuffrè, 5, 90127 Palermo, Italy. \\ E-mail: marco.giammanco@unipa.it
}

Key words: Thyroid hormone; 3,5-diiodo-L-thyronine; hepatic steatosis; nonalcoholic fatty liver disease; nutrition.

Contributions: All authors have read and agreed to the published version of the manuscript.

Acknowledgments: The authors want to acknowledge the Università degli Studi di Palermo (University of Palermo), Palermo, Italy.

Conflicts of interest: The authors declare no potential conflict of interests.

Abbreviations and acronyms: acetyl-coenzymeA-carboxylase (ACC); Acil-CoA oxidase (AOX); adrenocorticotropic hormone (ACTH); alkaline phosphatase (AP); AMP-activated protein kinase (P-AMPK); antioxidant response elements (ARE); body weight (BW); brown adipose tissue (BAT); carnitine palmitoyl-transferase system (CPT); catalase (CAT) cytosolic lipid droplets (CLD); Cytochrome C Oxidase (COX); hypothalamic-pituitary-thyroid axis (HPTA); 3,5 diiodo-L-thyronine (T2); free fatty acids (FFA); glutamic oxaloacetic transaminase (GOT); glutamic pyruvic transaminase (GPT); glutathione peroxidase (GPX); hypothalamic-pituitary-thyroid axis (HPTA); high density lipoprotein (HDL); high fat diet (HFD); hydroxypropyl cyclodextrin (HP-Cy); iopanoic acid (IOP); metallothionein (MT); metal response elements (MRE); monoiodotyrosine (MIT); nonalcoholic fatty liver disease (NAFLD); peroxisome proliferator-activated receptors (PPARs); perilipin1 (Plin1); perilipin 2 (Plin2); sodium-iodide symporter (NIS); superoxide dismutase (SOD); resting metabolic rate (RMR); reverse T3 (rT3); propylthiouracil (PTU $)$; rat hepatoma cell line $(\mathrm{FaO})$; sodium-iodide symporter (NIS); thyroid hormones (TH); type 1 iodothyronine deiodinase (D1); 3.5 diiodo-L-thyronine (T2); triiodothyronine (T3); thyroxine (T4); thyroid hormone receptors (TRs); thyroid peroxidase (TPO); thyroid stimulating hormone (TSH); triglycerides (TAG); TSH receptor (TSHR); white adipose tissue (WAT).

Received for publication: 14 June 2020.

Accepted for publication: 30 June 2020.

${ }^{\text {CC }}$ Copyright: the Author(s), 2020

Licensee PAGEPress, Italy

Journal of Biological Research 2020; 93:9182

doi:10.4081/jbr.2020.9182

This article is distributed under the terms of the Creative Commons Attribution Noncommercial License (by-nc 4.0) which permits any noncommercial use, distribution, and reproduction in any medium, provided the original author(s) and source are credited.

\begin{abstract}
Thyroid hormones have been proposed as anti obesity drugs due to their effects on basal metabolism and the ability to increase energy expenditure. However, their clinical use has been strongly curbed by the concomitant onset of thyrotoxicosis. In this setting, several studies have been undertaken to assess the role of 3,5 diiodo-L-thyronine (T2), an endogenous metabolite of thyroid hormone derived from the enzymatic deiodination of triodothyronine T3. The metabolic effects of T2 are similar to those induced by T3. However, these effects appear to involve different and not welldefined mechanisms that make this molecule clinically useful as potential drug in the treatment of pathological conditions such as obesity and hepatic steatosis. The main pharmacological target of T2 appears to be the mitochondria. Therefore, the administration of $\mathrm{T} 2$ to obese subjects might improve the mitochondrial performance, which is generally recognized to be reduced in these subjects who must oxidize greater quantities of substrates. In this context, it can be hypothesized that $\mathrm{T} 2$, by acting mainly on mitochondrial function and oxidative stress, might be able to prevent and revert the tissue damages and hepatic steatosis induced by a hyperlipidic diet and a concomitant reduction in the circulating levels LDL and triglycerides as well. This review the discuss the mechanisms of action of $\mathrm{T} 2$ and the possible, future clinical uses of T2 analogs for the treatment lipid dysmetabolism related to obesity and overweight.
\end{abstract}

\section{Introduction}

Obesity is an important risk factor for cardiovascular diseases, degenerative diseases and malignant diseases. ${ }^{1-5}$ Hyperalimentation can cause mitochondrial dysfunctions mainly in White Adipose Tissue (WAT). This may result in an altered substrate oxidation and increased oxidative stress with deleterious effects on metabolism. These phenomena may foster the development of obesity and that of associated pathologies. ${ }^{6-8}$ Thyroid hormones regulate several genes involved in lipolysis, lipogenesis, thermogenesis, mitochondrial function and nutrient availability. ${ }^{9,10}$ Due to their effects on the cardiovascular system and heart's rhythm, thyroid hormones, cannot be used as a pharmacological agents for the treatment of obesity. Many recent studies have highlighted that a metabolite of thyroid hormones, namely 3,5-diiodo-L-thyronine (T2) is endowed with interesting metabolic activities that may be of clinical interest as possible, future therapeutic option in the treatment overeating disorders. In this setting, experimental observations have shown that T2 administration to rodents caused an increase in resting metabo- 
lism ${ }^{11,12}$ and prevented overweight and insulin resistance induced by a hyperlipidic diet. ${ }^{13-15}$ Actually, sufficient data on the effects of T2 on the human body or possible beneficial effects on overweight, obesity and related diseases are still lacking. ${ }^{16-19}$ On the other hand, T2 has shown to exerts some dose-dependent effects on the physiological regulatory functions, however, the mechanisms underlying these effects are still not well understood. ${ }^{20-24}$ There is evidence that the administration of high doses of T2 to rodents can affect the hypothalamic-pituitary-thyroid axis (HPTA). ${ }^{20}$ Furthermore, the administration of $\mathrm{T} 2$ to rats fed a high-fat diet protects animals from the onset of hepatic steatosis. ${ }^{20}$ The use thyroid hormones, or its metabolites, for therapeutic purposes remains controversial as, in addition to beneficial effects on metabolism, these molecules may induce other non-metabolic effects mainly on the heart. On this purpose, recent studies have shown that treatment with levothyroxine in patients with heart failure was associated with an increased risk of mortality due to cardiovascular events. ${ }^{25}$ On the other hand, although the mechanism o action of this molecule on cellular metabolism remains to be unravelled, T2 remains of clinical interest. However, further investigations are needed to better define the clinical of T2 on humans and the optimal dose level to be administered to elicit the best therapeutic response of this molecule on the mitochondrial metabolism. Early studies carried out to define physiological role of T2, were previously overlooked given that, this molecule was considered only an inactive metabolite of thyroid hormones T3 and T4. This interpretation was based on the observations that T2 had a low affinity for nuclear receptors of thyroid hormones. This was the reason why most of the available studies were mainly dealt with the endogenous precursor of T2, namely Triiodothyronine (T3) as thyroid receptors showed to have a higher affinity for this form. However, in the late $80 \mathrm{~s}$, following the findings that thyroid hormones also had non-genomic effects i.e., independent from the nucleus, the role of T2 was re-evaluated. Consequently, many investigations now focusing on the metabolic effects of this molecule (Figure 1). ${ }^{26}$ Experimental observations suggest that T2 may spring from T3, while other in vitro, studies do not support this hypothesis. ${ }^{27}$ In fact, these investigations showed that the incubation of T3 with rat liver microsomes, i.e., a cellular fraction rich in type 1 deiodinases (the enzyme which removes an iodine atom from tyrosine and phenolic ring), generate 3,3'-diiodothyronine but not 3,5diiodothyronine. ${ }^{27}$ These and other similar findings were explained with the fact that: i) T3 may not be a precursor of T2; ii) the lacking, in vitro, of cofactors indispensable for catalyzing the conversion of $\mathrm{T} 3$ into T2. ${ }^{27}$ Therefore, in vivo studies have been carried out to better define the biochemical pathway that from T3 may lead to T2 formation. ${ }^{27}$ These experiments showed that the intraperitoneal administration of T3 to euthyroid animals induced an increase in the serum levels of T2, thus suggesting that T3 could be likely considered a metabolic precursor of T2. Furthermore, experimental findings by Horst et al. showed that, similarly as highlighted for T3, T2 induced a rapid stimulation of oxygen consumption in perfused livers of hypothyroid rats. ${ }^{28}$ The same studies showed that $t$ the effect of T3 was abolished when this hormone was administered to animals whose enzyme deiodinase was inhibited. On the other hand, under the same conditions, no change in the biological activity of T2 was reported. These data indicate that the peripheral deiodination of T3 is a key metabolic step in the production of T2, and that the latter has the same power as T3 but exerts its effect more rapidly. In this setting, further studies were carried out to better unravel the effects of T2 on energy metabolism and on cellular and mitochondrial respiration. The administration of $\mathrm{T} 2$, to experimental animals, induced more rapid effects on mitochondrial respiration than that obtained with T3. In fact, while T2 activity resulted evident one hour after the injection, T3 activity was evident only after $24 \mathrm{~h} .{ }^{29}$ Furthermore, studies carried out by O'Reilly, in rats, reported that the effect of T2 was independent from protein synthesis as it also occurred in presence of cycloheximide. ${ }^{30}$ These results indicate that the effects of T2 appear to be mediated by a direct interaction with the mitochondria, while those of T3 are mediated by interactions with the nucleus. Consequently, if T2 has a certain influence on the rate of energy consumption of the mitochondria, a plausible hypothesis is to attribute to the hormone a possible effect on the energy metabolism of the whole animal. This hypothesis is supported by the studies carried out in experimental animals by Tata in 1962 and $1963 . .^{31-33}$ These studies presupposed the monitoring and the comparison of changes occurring in the Rate of Rest Metabolism (RMR) following the administration of a single dose of T2 or T3 to hypothiroid rats. However, these experiments were not able to clarify whether the effects on RMR were effectively due to the hormones or to their metabolites. For this reason, in some experiments, deiodinases were simultaneously inhibited by the administration of Propylthiouracil (PTU) and Iopanoic acid (IOP). This induced the onset of a severe hypothyroidism in animals and, at the same time, a marked inhibition of all 3 types of deiodinases. In particular, PTU inhibited the production of thyroid hormones from the thyroid gland via inhibition of thyroid peroxidase activity, and at the same time, induced a strong inhibition of the enzyme type 1 iodothyronine deiodinase (D1). Conversely, IOP had no influence on the production of thyroid hormones. Hower, IOP showed to exert an inhibitory activity on all three forms of deiodinases including type 2 (D2) and type 3 (D3). ${ }^{34}$ Similar investigations showed that, in hypothyroid animals RMR was significantly reduced compared to euthyroid animals. Furthermore, the administration of T3 or T2 to hypothyroid animals significantly increased RMR although at a different rate. In fact, the administration of a single dose of $\mathrm{T} 3$ in rats, resulted in an increase of about $35 \%$ in the rate of resting metabolism which occurred $25-30$ hours after the injection of iodothyronine, with a peak effect reached after 50-75 hours, and which lasted up to 5-6 days after administration. On the other hand, the injection of T2 at the same dose level, induced a different response with an increase in the RMR of about $40 \%$ and that in this case occurred 6-12 hours after T2 administration, with a peak effect at 24-30 hours and a duration of 48h. Interestingly, these studies also demonstrated that the concomitant administration of Actinomycin D and T2 resulted in an inhibition of T3-induced stimulation of RMR, while the effect of the hormone on metabolism was preserved. ${ }^{35,36}$ These findings further support the hypothesis of a mechanism of action of 3,5-diiodothyronine that rule out the transcriptional processes and which is independent from the nucleus. Moreover, it can be hypothesized a possible involvement of T2 in the mediation of some short-term effects induced by thyroid hor-

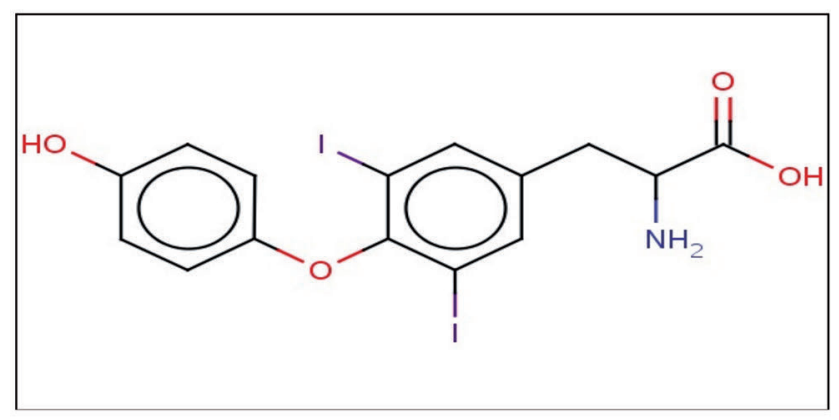

Figure 1. Structural formula of 3,5-Diiodothyronine (T2). 
mones in physiological situations where an increase in energy expenditure is required. An example would be the exposure to cold, a situation in which additional energy is required to counteract the increase in heat loss. In fact, thyroid hormones play an important key role in cold adaptation processes, as indicated by the experiments showing that hypothyroid rats survived to cold temperature only for 3-4 days. ${ }^{37}$ There is strong evidence that although with different mechanisms, both T2 and T3 may increase the resistance to cold. ${ }^{37}$ These phenomena have been defined by the studies by Lanni et al. whose results provided evidence that, in cold-exposed hypothyroid rats, $\mathrm{T} 2$ and $\mathrm{T} 3$ increased animal energy expenditure and stimulated the oxidative capacity expressed in terms of Cytochrome $\mathrm{C}$ Oxidase (COX) activity of tissues with a high metabolic rate such as heart, skeletal muscle, liver and Brown Adipose Tissue (BAT). ${ }^{37}$ However, while the stimulating activity of $\mathrm{T} 3$ on the trophism of tissues may probably due to nucleus-mediated effects, instead, the specific target of T2 appear to be mitochondria. This results in an improvement of the oxidative capacity of tissues. A further confirmation of the metabolic effects induced in vivo by $\mathrm{T} 2$, was provided by the experiments of Cimmino et al. related to the results obtained following a longterm treatments with T2 and T3, on the daily energy expenditure of non-anesthetized, hypothyroid rats and on the metabolism of amino acids and lipids of these animals. In order to assess the specific effects induced by T2 and T3 and to rule out those of their metabolites, hypothyroidism was induced in rats by the concomitant administration of PTU and IOP. Then, the daily energy expenditure was determined by continuous monitoring of $\mathrm{O}_{2}$ consumption and $\mathrm{CO}_{2}$ production. In hypothyroid rats, in which daily energy expenditure was low, the administration of $\mathrm{T} 2$ and $\mathrm{T} 3$ restored the normal values of euthyroid rats. The evidence that $\mathrm{T} 2$ is a metabolically active hormone was provided, in the same study, by the finding that $\mathrm{T} 2$ has stimulating effects on the lipid oxidation $\beta .^{38}$ All the effects of T2 reported above were observed in experiments carried out in rats with a deficit of thyroid function. The administration of the T2 to euthyroid rats induced no changes or only slight changes in $\mathrm{RMR} .{ }^{36} \mathrm{On}$ the other hand, different mechanisms might account for this phenomenon including: i) the elevated metabolic rate of T2; ii) the inability of diiodothyronine to enter cells; iii) In order to effectively interact with its cellular targets, this hormone needs to be produced from a precursor such as T3. The biochemical mechanism that leads to the formation of 3,5-diiodothyronine from 3,5,3'-triiodothyronine has not yet been demonstrated in vivo or in vitro; iv) the animal diet composition may affect the possibility to detect the metabolic effects of T2. In order to assess the time course of the calorific values of T2, Moreno et al. administered T3 to normal euthyroid rats $(\mathrm{N})$ and compared the results with those obtained following the administration of the same iodothyronine in hypothyroid-rendered animals in which the deiodynases were inhibited by administering propylthiouracil + iopanoic acid. These data of these studies showed that: i) the effect of T3 on RMR of $\mathrm{N}$ rats occurred approximately $25 \mathrm{~h}$ before those observed in rats treated with PTU + IOP; ii) The first phase of the change in resting metabolic rate of $\mathrm{N}$ rats treated with $\mathrm{T} 3$, appears to be very similar to that observed following T2 administration; iii) The inhibition of deiodinases following the concomitant administration of T3 and Actinomycin D to euthyroid rats (N), caused the inhibition of the late effects while the early effects were not affected; iv) the administration of T3 and actinomycin D to rats made hypothyroid by PTU + IOP treatments, caused a marked reduction of the early effects of the hormone, thus highlighting the need of deiodination to produce the early effect of T3; v) the highest increase in the rate of RMR concurred with the highest hepatic concentration of $\mathrm{T} 2$. This phenomenon was observed $\sim 25$ hours after $\mathrm{T} 3$ injection to euthyroid rats. Overall, these results indicate that the early increase in the rate of RMR occurring after the administration of $\mathrm{T} 3$ in $\mathrm{N}$ rats may be likely due to its conversion to $\mathrm{T} 2$ by deiodinases whose effect is independent of actinomycin D. Therefore, these findings indicated that the precursor of T2 in vivo, is T3. This phenomenon should not be overlooked as the genesis of diiodothyronine starting from T3 has never been observed in vitro. ${ }^{11}$

\section{Cellular Targets of 3,5-diiodo-L-thyronine (T2)}

Although the direct exposure in vitro of isolated mitochondria to $\mathrm{T} 2$ does not result in a regular stimulation mitochondrial activity, the hypothesis that these organelles could be the specific target of T2 is further supported by several observations. Experimental investigations, highlighted that, following a preincubation in vitro of liver homogenate with T2 and after the mitochondria were isolated, the hormone is able to induce a significant increase in the activity of of Cytochrome C Oxidase (COX) ${ }^{39}$ However, in order this phenomenon may occur, a cytoplasmatic factor, whose aim is that to mediate the effect of T2, is needed. The presence of T2binding cytosolic proteins was confirmed following the discovery, through photo-affinity labelling, of the binding sites for the hormone in the cytoplasm of rat liver cells. ${ }^{40}$ Following UV irradiation of rat liver cytosol, three proteins with different apparent molecular masses (86, 66 and $38 \mathrm{kD}$ ) able to covalently bind 3,5$\mathrm{T} 2$ were identified. Specifically, the $38 \mathrm{kD}$ protein was able to bind either T2 and T3, but its affinity for T2 was more elevated and its binding with $\mathrm{T} 2$ resulted independent of NADPH concentration. Conversely, the binding of the $38 \mathrm{kD}$ protein to triiodothyronine, was NADPH-dependent. Therefore, this cytoplasmic factor, by acting in a dependent manner on the cellular redox state (NADP/NADPH ratio), can function as a reservoir of T2 and T3 and as a carrier. ${ }^{40}$ Specific binding sites for T2 were also detected in rat liver mitochondria. This Binding sites has a high affinity $\left(10^{8}\right.$ $\mathrm{M}^{-1}$ ) and a low binding capacity (0.4-0.6 pmoles/mg protein). ${ }^{41}$ Competition analysis, evidenced that 3,3'-T2, T3 and T4 were also able to compete significantly with $\mathrm{T} 2$ for the same sites. However, this phenomenon occurred only in presence of high concentrations of iodothyronines. Nevertheless, according to Lanni et al. the results on the mitochondrial sites should be interpreted with some caution due to the intrinsic limitations in such studies. ${ }^{42}$ The study by the Goglia et al. describing the stimulating effects induced by the addition of $\mathrm{T} 2$ to the Cytochrome $\mathrm{C}$ Oxidase (COX) complex isolated from bovine heart mitochondria, led to the conclusion that this enzyme could be one of the targets of the hormone. ${ }^{41}$ This hypothesis was confirmed by Lombardi et al. (1988) who identified, two groups of reaction of the mitochondrial respiratory chain as targets of T2 namely the complex IV, also known as COX , which transfers electrons from the reduced cytochrome to $\mathrm{O}_{2}$ to produce $\mathrm{H}_{2} \mathrm{O}$, and the group of reactions involved in the reduction of cytochrome C. Furthermore, in the same year, Arnold et al. by using photoaffinity procedures, identified as the binding site of T2, the Va subunit of the COX complex. This was confirmed by using a monoclonal antibody against the Va subunit, in presence of which the binding of diiodothyronine to this subunit was prevented. ${ }^{43}$ The same study showed that the effects of $\mathrm{T} 2$ on the COX complex consisted in a suppression of the allosteric inhibition of cytochrome c oxidase by ATP, as the Va subunit is adiacent to the IV subunit which binds ATP. ${ }^{43}$ The effects of T2 could not directly involve also the mitochondria but they might be indirectly related to them. For example, the data obtained from Hummerich et al. indicate a possible an influence of $\mathrm{T} 2$ on mitochondrial activity 
that resulted in an increased absorption of mitochondrial $\mathrm{Ca}^{+2} \cdot{ }^{44}$ This, in turn triggered an enhancement of the mitochondrial activity due to the increased activity of the mitochondrial dehydrogenase. Consequently, there should be an increase in the number of reduced substrates available for the respiratory chain. ${ }^{45}$ The effects of $\mathrm{T} 2$ are not limited to mitochondria. In fact, Huang et al. compared the activity of thyroid hormone analogues on sodium $(\mathrm{Na}+)$ currents, in myocytes of newborn rats. These studies demonstrated that T4, T3 and T2 significantly increased $\mathrm{Na}+$ current as compared to control. In contrast, similarly as observed for reverse T3 (rT3), Monoiodotyrosine (MIT) or tyrosine the metabolites of T3 and T4 (TRIAC and TETRAC respectively) had no effect on $\mathrm{Na}+$ currents. As the effects of T3 and T2 were not blocked by propanol, these findings suggest that they are not mediated by the $\beta$-adrenergic signalling pathway. The authors suggested that the acute effects of thyroid hormones and their analogues on $\mathrm{Na}+$ currents could be mediated by a non-genomic thyroid hormone receptor, with a unique structure-activity relationship. The non-genomic action of T3 and T2 also affected the membrane transport systems (such as the $\mathrm{Na}+\mathrm{H}+$ exchanger, and the amino acid transport system) of chicken embryo hepatocytes. ${ }^{46}$ In line with these observations, Incerpi et al. provided evidence of rapid non-genomic effects of $\mathrm{TH}$ and suggested that the short-term effects of thyroid hormones play an important role during fetal development and in cellular differentiation. T2 was able, in this study, to mimic some of the effects of T3 but less efficiently. ${ }^{47}$

\section{T2 and lipid metabolism}

It is now well established that fatty acids increase the mitochondrial activity. Many studies have evaluated the role of a hyperlipidic diet in T2-treated rats to better assess the effects of this hormone on lipid metabolism. In one study, the data obtained from normal euthyroid rats receiving a standard diet $(\mathrm{N})$ were compared with those obtained from rats fed a high-fat diet (HFD) and from HFD rats treated with T2 (HFD-T2). These results clearly showed that in rats fed HFD-T2, T2 was able to reduce both adiposity and serum levels of free fatty acids, triglycerides and cholesterol without inducing any clinical signs of thyrotoxicosis. ${ }^{13,48}$ In HFD animals, $\beta$-oxidation levels resulted $30 \%$ higher, the activity of Acetyl-CoenzymeaCarboxylase (ACC) was significantly lower (-65\%) and the activity of Carnitine Palmitoyl-Transferase system (CPT) resulted $38 \%$ higher, compared to $\mathrm{N}$ animals. However, the levels of AMPActivated Protein Kinase (AMPK), which inhibited ACC activity in different physiological conditions, were decreased. The reduced ACC activity observed in HFD rats was probably due to a reduced amount of the enzyme, rather than to its decreased activity. This suggests that the increase in fatty acid oxidation in HFD rat may be due to a malonyl-CoA-dependent mechanism i.e., reduced ACC content $\rightarrow$ reduced level of malonylCoA $\rightarrow$ activation of the CPT system. ${ }^{13,48}$ In HFD-T2 animals, the ACC activity was not further decreased as compared to HFD animals, despite the increase in AMPK content, CPT activity ( $52 \%$ vs HFD and $+110 \%$ vs N) and $\beta$ - oxidation $(+42 \%$ vs HFD and $+93 \%$ vs $N)$. Therefore, T2 appeared to be able to further increase fatty acid oxidation by significantly activating AMPK and CPT activity but without increasing CPT1 mRNA levels and without further inhibiting ACC activity. ${ }^{13,48}$ These results seem apparently to rule out an involvement of the AMPK-ACC-CPT pathway on the effects of HFD and T2 on liver fatty acid oxidation observed after 30 days. However, it can be hypothesized that $\mathrm{T} 2$ could increase the entering of fatty acids in the mitochondria by regulating CPT1 activity in a AMPK-dependent manner and ACC-malonyl-CoA in a independent manner. ${ }^{13,48}$ The possible existence of a malonyl-CoA-independent control mechanism on the hepatic activity of CPT1 is supported by some recent studies which showed that stimulation of hepatic oxidation of fatty acids can also use an independent malonyl-CoA pathway, which includes an AMPK-mediated phosphorylation by cytoskeletal components, that lead to CPT1 stimulation..$^{15,49,50}$ The increase in body weight and adiposity observed in HFD rats, clearly indicate that the increase in hepatic fatty acid oxidation is not per se sufficient to prevent fat accumulation, due to HFD consumption and that, in HFD$\mathrm{T} 2$ animals the reduction of adiposity could be related to a less efficient use of the substrate. ${ }^{13,51}$ In fact, as mentioned above, in addition to the stimulation of the oxidation of fatty acids in the liver, T2 caused a less efficient use of lipid substrates through the stimulation of thermogenic mechanisms such as decoupling of mitochondrial complex (loss of protons). This phenomenon lead to a lower synthesis of ATP and a greater fat combustion, which resulted to be more elevated in HFD-T2 than in HFD rats. ${ }^{51}$ The physiological consequence of these effects were an increase in energy expenditure and a slight increase of body temperature. This suggested that proton loss had a decisive role in the effects exerted by $\mathrm{T} 2$ on substrate utilization efficiency and, consequently, on adiposity. Thus, T2 may be able to induce in HFD rats a reduction in the accumulation of fat in the liver and a marked reduction in the mass of adipose tissue. It is worth to note also a T2-induced reduction of serum levels of Triglycerides (TAG), Free Fatty Acids (FFA) and cholesterol. ${ }^{13}$ To assess the hypothesis that the effects of $\mathrm{T} 2$ in reducing the accumulation of excess lipids, previously observed in primary rat hepatocytes could depend on a non receptorial mechanisms, ${ }^{52}$ recent investigations were carried out on a well differentiated rat hepatoma cell line $(\mathrm{FaO})$ which lacks of functional Thyroid Receptors (TRs), ${ }^{53}$ In humans and rodents, TRSs are encoded by two genes. The THRA gene encodes three isoforms, but only TR $\alpha 1$ binds T3, ${ }^{54,55}$ whereas the THRB gene encodes two variants, TR $\beta 1$ and TR $\beta 2$ respectively. ${ }^{56,57}$ In a previous study carried out in T3-treated knockout mice for TR $\beta$, showed that the expression of a large number of genes was induced by thyroid hormones even in the absence of TR $\beta 1 .{ }^{58}$ In the liver, TR $\alpha 1$ levels are much lower than those of TR $\beta 1$ and most of the effects of thyroid hormones are mediated by the TR $\beta 1$ isoform. A characteristic of the receptor-independent mechanisms of iodothyronines is the plurality of thyroid derivatives, including T2, and/or that of functional analogues and that they can trigger specific effects and could be more potent than T3 itself. ${ }^{59} \mathrm{~T} 2$, like T3, when injected into the isolated and perfused liver, or when added to mitochondria isolated from hypothyroid rats, may foster the rapid hepatic oxygen diffusion. ${ }^{11,28}$ Effects similar to those of T3 were observed in hepatocytes isolated from hypothyroid animals. ${ }^{60} \mathrm{~A}$ first step of this study consisted to assess in $\mathrm{FaO}$ cells the absence of constitutive mRNA expression for both TR $\alpha 1$ and TR $\beta 1$ by comparing their mRNA levels with those determined in rat liver. The results further confirmed that in $\mathrm{FaO}$ cells, the levels of mRNA transcripts for TRs are negligible when compared to that of rat liver. Therefore, an in vitro model of "steatosis" was developed by exposing $\mathrm{FaO}$ cells for 3 hours to a mixture of oleate/palmitate ( 0.75 final $\mathrm{mM}$ concentration), which closely mimics plasma FFA levels of patients with metabolic syndrome. ${ }^{61,62}$ FFAs taken up by hepatic cell are converted, in the cytosol, into TAGs and stored in the form of Cytosolic Lipid Droplets (CLD). FFAs that enter the liver undergo esterification to produce TAGs or, alternatively, oxidation, to generate ATP. The TAGs, in turn, are accumulated in form of CLD. Typically, CLDs are composed of a nucleus of neutral lipids surrounded by phospholipids and proteins of the PAT family [Perilipin, also known as perilipin 1 
(PLIN1); Adipophilin or perilipin 2; TIP47 that is, perilipin]. Among these proteins, those related to adipocytic differentiation (ADRP, also known as PLIN2) represents the most important proteins present in human and mouse liver. The expression of ADRP is increased in Non Alcoholic Fatty Liver Disease (NAFLD) ${ }^{63}$ and is under the control of Peroxisome Proliferator-Activated Receptors (PPARs), which are transcription factors that regulate lipid metabolism. PPARs act as transcription factors for ADRP, ${ }^{64,65}$ a PAT protein that promotes lipid incorporation in CLD and inhibition of FAA oxidation. ${ }^{66}$ When $\mathrm{FaO}$ cells loaded with lipids were treated with $\mathrm{T} 2$ or T3 for $24 \mathrm{~h}$, TAG content was reduced to levels comparable with those observed in control cells. This demonstrates that the direct hypolipidizing effect exerted both by $\mathrm{T} 2$ and $\mathrm{T} 3$ on the hepatic cell can occur even in the absence of TRs. The effects of $\mathrm{T} 2$ and $\mathrm{T} 3$ on $\mathrm{O}_{2}$ consumption in liver cells that do not express TRs were also evaluated. The results clearly indicated that the addition of both iodothyronines to intact hepatocytes induced a rapid decoupling of phosphorylation from oxidation. These data demonstrate the decoupling effect of T2 and T3 in intact hepatocytes, in presence of adequate substrate and of $\mathrm{O}_{2}{ }^{67} \mathrm{In}$ addition, to the short-term effects on mitochondria, thyroid hormones exert pleiotropic effects on lipid metabolism. In the liver, thyroid hormones stimulate enzymes that regulate both lipogenesis and lipolysis. Peroxisome proliferator-activated receptors (PPARs) play a key role in lipid metabolism; PPAR $\alpha$ improves catabolism and lipid mobilization, ${ }^{68}$ while PPAR $\gamma$ promotes lipid synthesis and CLD formation. ${ }^{69,70}$ Furthermore, PPAR $\beta / \delta$ play a crucial role in hepatic lipid homeostasis and in insulin sensitivity, by activating glycolysis and lithogenesis. ${ }^{71}$ Therefore, the transcription profiles of the three receptor subtypes, PPAR $\alpha, \operatorname{PPAR} \gamma$, and PPAR $\delta$ were evaluated in $\mathrm{FaO}$ cells under different experimental conditions. All the subtypes were constitutively expressed in $\mathrm{FaO}$ rat hepatoma cells. However the expression levels of PPAR $\alpha$ and PPAR $\delta$ resulted more elevated as compared to PPAR $\gamma$. The accumulation of excess lipids in $\mathrm{FaO}$ cells led to an up-regulation of PPAR $\gamma$ mRNA, a down-regulation of that of PPAR $\delta$, while PPAR $\alpha$ remained unchanged. These data were in line with the role of PPAR $\gamma$ in promoting lipid accumulation. ${ }^{69,70}$ On the other hand, the reduction of PPAR $\delta$ expression observed in lipid-loaded $\mathrm{FaO}$ cells were consistent with with o previous data showing an opposite regulation of PPAR $\delta$ and PPAR $\gamma$ in ob /ob mice. ${ }^{72}$ PPAR $\delta$ increased the synthesis of high-density lipoprotein (HDL), inhibited CLD formation in the liver, improved FFA catabolism and promoted energy decoupling in adipose and muscular tissues. ${ }^{73,74}$ Murine models of fatty liver usually express increased PPAR $\alpha$ levels. The absence of upregulation of PPAR $\alpha$ in $\mathrm{FaO}$ cells loaded with lipids may depend on a presence of an excess in oleate compared to palmitate $(2: 1)$ in the FFA mixture. The excess of oleate can also explain the decrease in steroid-CoA-desaturase transcription observed in lipid-loaded $\mathrm{FaO}$ cells, since this enzyme synthesizes oleic acid. ${ }^{52}$ Therefore, the concomitant down-regulation of PPAR $\delta$ and the up-regulation of PPAR $\gamma$ in lipid-loaded $\mathrm{FaO}$ cells might account for the inhibition of FFA oxidation, the release of VLDL and their accumulation in CLD. Overall, the different transcription model of the three subtypes of PPARs suggests that, in this in vitro model of hepatic steatosis, the process of $\beta$-oxidation via mechanisms mediated by PPAR $\alpha$ and PPAR $\delta$ in the hepatocyte, are negligible, as confirmed by the lack of significant downstream changes in the expression of the lipolytic gene Acyl-CoA oxidase (AOX). However, the storage of fat in excess in CLD may occur probably through mechanisms mediated by PPAR $\gamma$. Treatment of lipid-enriched $\mathrm{FaO}$ cells with iodothyronines leads to a decrease in TAG content. The up-regulation of PPAR $\gamma$ induced by FFA is inhibited following a 24-hour incubation with T2 and T3, which also decrease the expression of mRNA for
PPAR $\alpha$ by up-regulating the expression of PPAR $\delta$. In light of the role of PPAR $\delta$ in promoting HDL synthesis, FFA catabolism, energetic decoupling and in inhibiting the formation of CLD, these data indicate that in lipid-loaded hepatocytes, both iodothyronines can foster the stimulation of FFA catabolism and energy decoupling while, at the same time, decrease the formation of CLD. Furthermore, the decrease in intracellular lipid content induced by both T2 and T3 is associated with changes in lipoprotein synthesis and the rate of exocytosis of VLDL. Of interest is their effect on the characteristic size of the CLD of fatty hepatocytes. A reduction in the average size after treatment with iodothyronines was observed, suggesting that T2 and T3 may act in the dispersion/fragmentation of CLDs. A decrease in the size of CLDs could make the accumulation of TAGs more accessible for enzymes that act on lipid catabolism. This could explain, at least partially, the ability of iodothyronines to decrease the fat in excess in the liver, by acting directly on the liver cell. Therefore, the reduction of the lipid content observed in $\mathrm{FaO}$ cells of rat hepatoma which is due to iodothyronines is achieved through non-receptorial mechanisms either in the short term, through stimulation of mitochondrial $\mathrm{O}_{2}$ consumption, and in the long term, through different effects on PPARs transcription. Ultimately, these effects may, in turn, activate those pathways that affect TAG deposits within CLDs and that promote mitochondrial oxidation and/or exocytosis of VLDL. ${ }^{75}$ As 3,5-T2 results as effective as $\mathrm{T} 3$ in reducing lipid content in lipid-loaded $\mathrm{FaO}$ cells and, due to the lack of thyrotoxic effects, this molecule may be considered of clinical interest in the pharmacological treatment of dysmetabolic syndromes such as NAFLD. ${ }^{38,59}$ NAFLD is a pathological condition widespread in opulent societies, which is characterized by altered lipid metabolism, and consequent accumulation of fat in hepatocytes, increased oxidative stress and abnormal production of cytokines. ${ }^{76}$ It is associated with visceral obesity and various cardiovascular risk factors. ${ }^{1}$ This condition can also evolve into steatohepatitis, advanced fibrosis, cirrhosis, and finally hepatocellular carcinoma. ${ }^{77}$ Although the modulation of the caloric intake and increase of physical activity are the cornerstones of the treatment of metabolic disorders, in recent years data from various experimental and clinical investigations suggest that different drugs could be useful for the prevention and/or treatment of steatosis. Since mitochondrial dysfunction is crucial to the pathophysiology of steatosis and steatohepatitis, drugs or other factors that directly or indirectly improve mitochondrial function may be useful in the prevention and/or treatment of these liver diseases. In this setting, some experimental investigations were undertaken, in which steatosis and mitochondrial parameters were evaluated in rats fed a high percentage of fats over a long period and treated with T2 up to 4 weeks and fed the same high-fat diet. $^{78}$ The results clearly indicate that in these animals T2: i) reduced body weight and metabolic efficiency without suppressing TSH levels; ii) decreased the serum levels of cholesterol, TAG and ALT; ii) increased the hepatic mitochondrial consumption of $\mathrm{O}_{2}$ and oxidation of fatty acids; iv) activated the proton mitochondrial loss in hepatocytes; v) reduced the mitochondrial oxidative stress. The ectopic development of fat storage in the liver, induced by a diet rich in fat, was associated with alterations in the mitochondrial compartment. In fact, steatotic rats showed a reduced respiratory capacity and an increase in oxidative stress in hepatic mitochondria, although the ability to use fat as a metabolic fuel was increased. Due to the increased hepatic absorption of FFAs that occurs during a high-fat diet, the mitochondrial the increase in fatty acid oxidation and ketogenesis, observed in fatty liver, would act as a compensatory mechanism. This also occurred in patients with steatohepatitis. ${ }^{79,80}$ An increased mitochondrial $\beta$-oxidation has been also observed also in the liver of genetically obese (ob/ob) mice, with massive steatosis. ${ }^{81}$ 
However, the increase in lipid oxidation is not sufficient to handle the increased burden of hepatic FFAs, so the remaining FFAs are converted into triglycerides, which are partly deposited in the cytoplasm, thus causing steatosis. An interesting aspect concerns the changes in efficiency of substrate utilization. In fact, a decrease in proton loss and an increase in the body weight/caloric intake ratio clearly indicate a more efficient use of energy in steatotic animals than in controls. On the other hand, after T2 treatment, the efficiency in the energy use resulted clearly decreased. Furthermore, in line with the decrease in TAG content in the liver, serum cholesterol, TAG and ALT levels were significantly reduced. The effect of T2 on mitochondrial efficiency in the liver cannot be attributed to an induction of the expression of UCP2 and UCP3, which have been proposed by some authors as mediators of a decoupling effects, since neither UCP2 nor UCP3 were found to be expressed. ${ }^{82,83}$ Therefore, the mechanism underlying the decoupling effect of $\mathrm{T} 2$ remains to be clarified, although previous studies showed that the addition of T2 in a reconstituted complex of COX led the complex to a decrease in the respiratory control ratio. ${ }^{84,85}$ At mitochondrial level, the administration of T2 for four weeks induced a further increase in $\beta$-oxidation and CPT system activity. These increases, responsible of a better compensation of the hepatic load of FFAs, could be one of the mechanisms that make T2 able to improve steatosis. Furthermore, the increase in the rate of mitochondrial respiratory processes could enhance the reoxidation of NADH, a coenzyme necessary for both $\beta$-oxidation and the tricarboxylic acid cycle. ${ }^{86}$ This mechanism, coupled with a less efficient and concomitant use of substrates, through a stimulation of both basal and FFA-induced proton loss, would lead to a higher fat consumption. ${ }^{87}$ All these effects promote a better compensation of the load of liver FFA and could represent one of the mechanisms through which T2 may improve steatosis. Furthermore, the increase in the rate of oxidation could lead to the re-oxidation of $\mathrm{NADH}$, the coenzyme involved both in $\beta$-oxidation, and in the cycle of tricarboxylic acids. ${ }^{86} \mathrm{An}$ increase in proton loss and consequently a decrease in membrane potential, which may be probably due to the increased activity of UCP2, may results in the reduction of an excessive formation of ROS. ${ }^{88,89}$ The data by Mollica et al. reveal that the administration of $\mathrm{T} 2$ determines a lower hepatic mitochondrial oxidative stress, as indicated by the significant decrease of $\mathrm{H}_{2} \mathrm{O}_{2}{ }^{87}$

\section{Effects of T2 on lipid peroxidation}

Chronic exposure of rats to lipid-lowering drugs (ciprofibrate) often leads to hepato-carcinogenesis, probably due to an overproduction of $\mathrm{H}_{2} \mathrm{O}_{2}$. In fatty hepatocytes, the decrease in iodothyronine-induced lipid excess was accompanied by a decrease in the stimulation of peroxisomal AOX activity. This is particularly important because it may represent a beneficial effect due to the decrease in ROS production. In fact, high FFA oxidation rates can lead to an increase in the production of reactive oxygen species (ROS) at the peroxisomial, mitochondrial and microsomal levels. ${ }^{90}$ After the addition of iodothyronine, the activities of Superoxide Dismutase (SOD) and Catalase (CAT) were reduced compared to fatty hepatocytes unexposed to iodothyronine. This suggests that iodothyronines have a protective effect on the possible consequences of peroxisomal oxidation of FFA, with consequent reduction in the production of peroxy radicals, associated with an excess of fat in hepatocytes..$^{52,91}$ The hepatic cell try to hinder the cellular oxidative stress by increasing the activity/expression of antioxidant enzymes and/or by inducing the synthesis of antioxidant molecules such as glutathione and metallothioneins. ${ }^{92}$ Low-molecular weight metallothioneins (MT) (6-7 kDa) are highly conserved ubiquitous proteins rich in cysteine with high affinity for divalent metals ${ }^{93}$ which are involved in some essential biological functions, including homeostatic regulation of zinc and copper, detoxification from heavy metals, and scavenging of free radicals. ${ }^{94}$ The mobilization of zinc by MTs through oxidizing agents may explain the in vivo antioxidant activity of MTs. ${ }^{95}$ A number of stimuli induce their expression, including acute phase response, cold, heat, stress and some hormones, such as GH. ${ }^{93}$ Furthermore, transgenic mice over-expressing MT are more protected from hepatic oxidative stress associated with alcoholic liver disease. ${ }^{96}$ Four MT (MT-1 MT-4) isoforms encoded by four functional genes have been identified in rodents. The different isoforms appear to have distinct functions under different physiological and pathological conditions. The dynamic nature of the metallothionein/thionine (MT/T) system, and the observation that MT I/II knockout mice become mildly obese, suggest a role for MTs as modulators of energy metabolism. ${ }^{97-99}$ Some studies investigated the association between reduction in fat accumulation in the liver of HFD-fed rats induced by $\mathrm{T} 2$ inoculation, changes in oxidative stress and MT expression. Body weight, serum TAGs, lipid accumulation in the liver, and PPAR $\alpha$ expression were evaluated in rats fed HFD, treated with T2 and the changes occurring in these animals were compared with those obtained in control rats. The effects of HFD and T2 on the level of hepatic lipid peroxidation [thiobarbituric-reactive substances (TBARS)] and on the activity of antioxidant enzymes responsible for detoxification from hydrogen peroxide (H2O2), i.e., CAT and glutathioneperoxidase (GPX), were also evaluated. The transcription levels of the main MT isoforms in the liver (MT-1 and MT-2) were also assessed by RT-PCR. ${ }^{91}$ FFAs activated the transcription of PPAR $\alpha$ which modulated the metabolism of fats at different levels by altering the transcription of numerous genes, many of which are involved in the catabolism of the same FFAs. ${ }^{100,101}$ A high-fat diet presumably provides more long-chain FFAs capable of entering hepatocytes, thus inducing an upregulation of PPAR $\alpha$. The expression of PPAR $\alpha$ is also up-regulated in the liver of obese rodents fed diets rich in fat. ${ }^{102-105}$ This effect has been also highlighted in the liver biopsies of patients with NAFLD. ${ }^{106}$ In line with these data, a high-fat diet induced the expression of PPAR $\alpha$ in rat liver. After a 30 days treatment with $\mathrm{T} 2$, the upregulation of PPAR $\alpha$ induced by the high fat diet was reduced. This effect paralleled the reduction of lipid droplets accumulation observed in tissue section of liver of T2-treated rats compared to HFD rats. The increased oxidation of fatty acids usually leads to greater production of peroxy radicals and consequently of oxidative stress. ${ }^{100,107}$ In fact, an increase in lipid peroxidation in the liver of HFD rats was observed, as well as a stimulation of the activity of CAT and Se-dependent GPX. All these effects were partially neutralized by the administration of T2 to rats fed HFD. In contrast, in line with previous data which showed an increase in mitochondrial oxidation of fatty acids, ${ }^{13}$ in the liver of HFD rats treated with $\mathrm{T} 2$, an increase in mitochondrial $\mathrm{H}_{2} \mathrm{O}_{2}$ production was observed. Peroxisomes are the main site for long and very long chain fatty acid oxidation, the main component of food lipids. On the other hand, long-chain fatty acids require the activity of CPT, to enter the mitochondria. CPT activity is stimulated by a hyperlipidic diet and is further stimulated by T2. This indicates the activation of CPT as a key step in mitochondrial stimulation of the catabolism of fatty acids by T2. ${ }^{13}$ MTs represent a main component of the non-enzymatic antioxidant system of the cells. ${ }^{94}$ They play a key role in liver damage, liver regeneration, ${ }^{108,109}$ and energy metabolism as well. ${ }^{98,110}$ The evaluation of the transcription profiles of the two isoforms constitutively expressed in the liver 
namely, MT-1 and MT-2, highlighted also an up-regulation of both isoforms in hyperlipidic diet rats, thus suggesting the protective role of MTs in the liver. ${ }^{111}$ The concomitant administration of T2 to rats with a hyperlipidic diet partially thwarted the up-regulation of MT-2, but not that of MT-1. The observation that T2 does not alter the transcription profile of MTs in the liver of rats fed a standard diet suggests that the effects of T2 on hepatic expression of MTs are secondary to the effects of the hormone on molecules and/or pathways associated with fat intake. The up-regulation of MTS induced by the hyperlipidic diet could be due to an imbalance in the level of essential metals and/or conditions of oxidative stress. However, no significant changes were observed in total hepatic zinc and copper levels correlated with the hyperlipidic diet and/or treatment with T2. This indicates a crucial role of these metals in the up-regulation of MTs induced by a hyper-lipid diet. However, possible changes in the availability of free (rapid exchange) zinc ions induced by the hyperlipidic diet cannot be also ruled out. Thus, oxidative stress appears to be the possible candidate involved in the up-regulation of MTs transcription. This has been well established for MT-2, while MT-1 remains over expressed in rats with a hyperlipidic diet, independently of the reduction in lipid accumulation and the oxidative stress associated with T2 administration. Furthermore, a previous study showed that MT-2 mRNA levels in adipose tissue was increased in obese subjects. ${ }^{12}$ Overall, previous observations and current results indicate a specific role of the MT-2 isoform in the defence mechanism against oxidative stress. However, the regulation of MTs gene expression is rather complex and involves numerous transcription factors, signalling pathways, and response elements (RE). ROS can induce the expression of MTs through the interaction with the antioxidant response elements (ARE) and with the metal response elements (MRE), ${ }^{113}$ of the MTs genes, as well as through different transcription factors sensitive to the cellular redox state. ${ }^{114}$ At present, the molecular mechanisms responsible for the regulation of MT-1 and MT-2 transcription, as well as their functional implications, are not yet clear. The relationship between MT-2 transcription, fat oxidation and oxidative stress could be related to the different scavenging activities performed by the two MTs iso-forms in vitro, with MT-1 representing a more selective scavenger towards $\mathrm{O}_{2} \cdot$ and MT -2 against $\cdot \mathrm{OH} .{ }^{115} \mathrm{It}$ is worth noting that MTs are located in the intermembrane space of the mitochondria of the liver cells, suggesting a role for these proteins in the fine-tuning of the mitochondrial energetic metabolism, by reversibly modulating the site for zinc. ${ }^{97}$ The effects of T2, i.e., prevention of fat accumulation induced by the hyperlipidic diet, partial neutralization of the up-regulation of PPAR $\alpha$ and MTs and of oxidative stress, can be explained by a selective stimulation exerted by $\mathrm{T} 2$ on the metabolism of fatty acids in the mitochondria to the detriment of peroxisomal and microsomal oxidation. However, it is conceivable that the effects of T2 on the liver are indirect and may depend on a reduced influx of fat in hepatocytes caused by a primary effect of T2 in other tissues, such as on adipose tissue. Further studies reported that rats with hepatic steatosis also showed a mitochondrial increase in oxidative stress parameters such as increased $\mathrm{H}_{2} \mathrm{O}_{2}$ production, and inhibition of aconitase and SOD activity. ${ }^{87}$ Furthermore, T2 administration reduces mitochondrial oxidative stress. Consistent with these findings, in hyperlipidic diet rats treated with $\mathrm{T} 2$, the formation of $\mathrm{H}_{2} \mathrm{O}_{2}$ is reduced, as well as the total basal aconitase /total aconitase ratio, while the SOD activity increased compared to those with a non-treated hyperlipidic diet. Furthermore, an increase in SOD activity was observed in rats with hyperlipidic diet treated with $\mathrm{T} 2$, although, in control rats these values did not return to basal levels.

\section{Conclusions}

3,5,3'-triiodothyronine (T3) has long been considered potentially useful for the treatment of obese patients as it determines an increase in the metabolic rate and causing a reduction in body weight. ${ }^{116}$ Indeed, it is well known that T3 stimulates carbohydrate and protein lipid metabolism and increases energy expenditure. However, the onset of serious side effects has limited its use. ${ }^{116}$ Attempts to eliminate most of the side effects, especially those related to the cardio-circulatory system, through the administration of $\beta$-blockers failed to prevent the excessive decrease of the lean body mass. In this context, a growing number of studies has been undertaken to assess the effects of T2, a T3 metabolite, once considered inactive, but that studies on metabolism of animal models has been shown to be effective in increasing the resting energy. ${ }^{29}$ The peculiar characteristic of T2 is its nucleus-independent activity, which is markedly different from that of T3 which, conversely, is mainly mediated by the nucleus. The discovery of prepared the way to a potentially valid therapeutic scenario. In fact, similarly to T3, T2 promotes energy loss. However, unlike T3, it does not act by a nucleus-mediated mechanisms, rather by a process that involve mitochondrial proton loss. ${ }^{13}$ In line with these observations, several experimental observations have reported that the administration of $\mathrm{T} 2$ to rats fed with high fat diet, did not induce side effects typical of thyrotoxicosis. ${ }^{13}$ These phenomena may be explained, with the observation that although T2 has a lower affinity for nuclear receptors than T3, the former may stimulate cellular metabolism through mechanisms that involve the mitochondrial apparatus. Studies carried out in rats fed on a diet high in fat and subject to long term treatments with $\mathrm{T} 2$, showed a reduction in adiposity and in body weight without the onset of thyrotoxic effects. ${ }^{117}$ By the use of a TRH test, it was highlighted that following TRH injection there was no significant difference in the serum levels of THS between rats fed a hyperlipidic diet, rats fed a standard diet and rats with a hyperlipidic diet administered with T2, thus indicating that the hypothalamic-pituitary-thyroid axis was not compromised after treatment with diiodothyronine (dosedependent effect). Thyroid and heart weight values did not significantly differ from those determined in normal euthyroid rat, whereas white visceral fat and liver weight were significantly decreased in rats fed with fat diet and T2. Furthermore, no change in heart rate was observed after administration of T2. ${ }^{13}$ Bearing in mind that the main target of T2 appears to be mitochondria, the decrease in mitochondrial efficiency indicates that, when, during overeating there is an excess of FFA that reaches the liver, in order to produce the same amount of ATP, the mitochondria must oxidize a higher amount of substrates. The decoupling between oxidation and phosphorylation is a biological mean useful to dissipate the substrate energy (including lipids) in form of heating and to oxidize a greater amount to produce the same quantity of ATP. Consequently, a greater amount of fatty acids that reach the liver are directed towards oxidation instead of restoring. Therefore the treatment with $\mathrm{T} 2$ may prevent and reverse the damage caused by a hyperlipidic diet and reduce the circulating levels of LDL, triglycerides and hepatic steatosis in overweight patients, with high levels of LDL, with hypertriglyceridemia and/or steatosis), by acting on mitochondrial function and oxidative stress. Therefore, T2 may be of potential clinical interest as novel drug for the treatment of the pathological conditions mentioned above. Therefore, the use of T2 could be regarded as an useful pharmacological approach for the prevention or treatment of diseases associated with a diet high in fat, such as non-alcoholic fatty liver disease. It has been proven 
that the hormone may reduce a pre-existing accumulation of fat in the liver. ${ }^{20}$ In humans, few studies have confirmed that the administration of $\mathrm{T} 2$ can increase the resting metabolic rate, reduce adiposity and body weight without side effects. ${ }^{87}$ Experimental studies in high-powered rats, have also shown that, unlike in hyper-fed rats not exposed to $\mathrm{T} 2$ that showed hepatic steatosis, the administration of high doses of T2 did not cause steatosis. ${ }^{20}$ In this setting Giammanco et al. carried out some experiments on three groups of male Wistar rats. One group received a standard diet, one group was fed a high-fat diet, and the third group received a high-fat diet three days a week and a dose of T2 (70 mgr/100 g BW). The administration of $70 \mathrm{mg}$ of T2/100 gr BW suppressed TSH secretion and prevented the onset of steatosis in rats with a hyperlipidic diet and treated with T2 (Figure 2 and 3). ${ }^{20}$ Recently, T2 analogues have been designed and synthesized in the perspective to identify novel and effective therapeutic options in the treatment of these pathologies. ${ }^{59}$ The results of one of these study, namely TRC150094 or more simply TRC. ${ }^{59}$ showed that the administration of TRC to rats fed a hyperlipidic diet resulted in a reduction in the accumulation of fats in the liver, adipose tissue, cholesterol and triglyceride blood levels. Of course, clinical studies are needed ensuring the complete safety of patients to TRC treatment. Research on the effects of human metabolism is still scanty while,

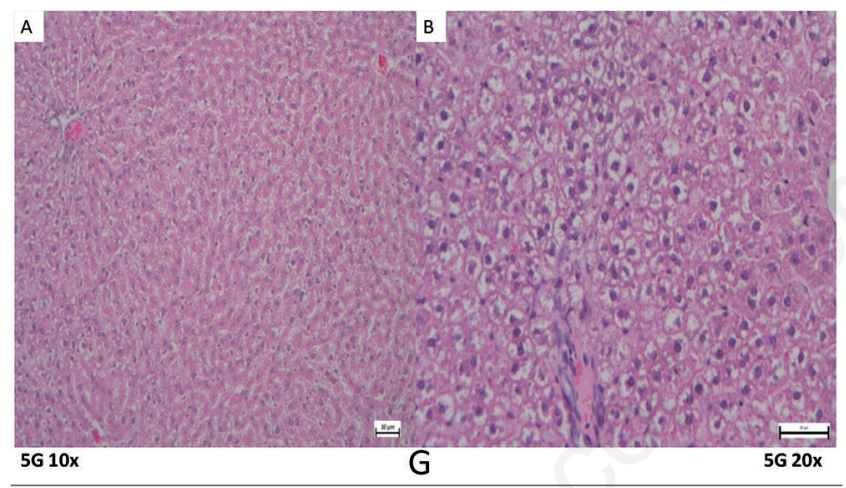

Figure 2. Histological sections of liver tissue from high fat diet fed rats. Note the widespread intracellular vacuolization of hepatocytes and the resulting relocation of cell nuclei in a peripheral position (score 2). (from Giammanco et al. 2016).

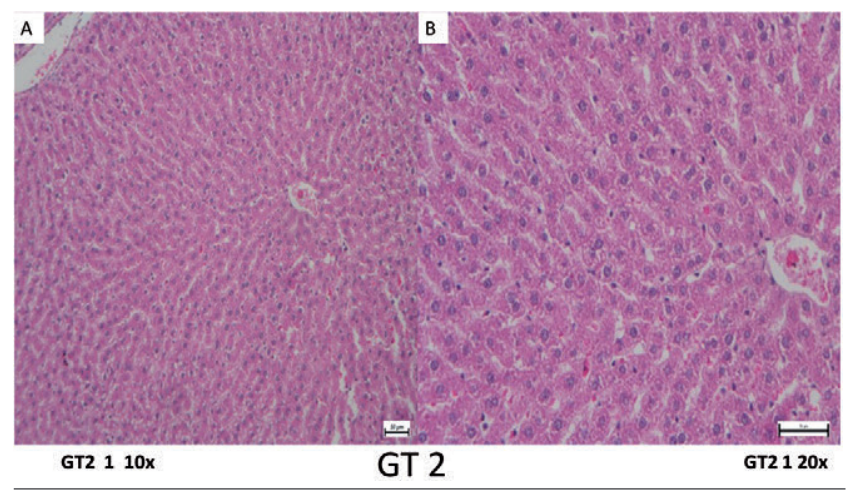

Figure 3. Histological sections of liver tissue from high fat diet fed rats and administered three times a week with $70 \mu \mathrm{g}$ per $100 \mathrm{gr}$ BW. No evident sign of steatosis is observed. (from Giammanco et al. 2016). studies on humans are needed. Therefore, much work still needs to be done before marketing a thyroid hormone-based drug that show to have beneficial effects on diseases related to fat metabolism, mainly in obese subjects.

\section{References}

1. Giammanco M, Lantieri L, Leto G, et al. Nutrition, obesity and hormones. J Biol Res - Boll Soc Ital Biol Sper 2018;91: 108-18.

2. Giammanco G, La Guardia M, Martorana S, et al. How cognitive behavioural therapy can modulate negative emotional factors as anxiety or depression in obese patients. J Biol Res - Boll Soc Ital Biol Sper 2015;88;2015:76-7.

3. Russo G, Di Majo D, Giammanco M. Could a wrong consumption of cereals influence preteens obesity in Sicily? J Biol Res - Boll Soc Ital Biol Sper 2015;88:131-2.

4. La Guardia M, Giammanco M. Breast cancer and obesity. Panminerva Medica 2001;42:123-133.

5. Tabacchi G, Giammanco S, La Guardia M, Giammanco M. A review of the literature and a new classification of the early determinants of childhood obesity: from pregnancy to the first years of life. Nutr Res 2007;27:587-604.

6. De Pauw A, Tejerina S, Raes M, et al. Mitochondrial dysfunction in adipocyte dedifferentiation and systemic metabolic alterations. Am J Pathol 2009;175:927-39.

7. Paglialunga S Ludzki A, Root-McCaig J, Holloway GP. In adipose tissue, increased mitochondrial emission of reactive oxygen species is important for short-term high-fat dietinduced insulin resistance in mice. Diabetologia 2015;58: 1071-80.

8.Chattopadhyay M, Khemka VK, Chatterjee G, et al. Enhanced ROS production and oxidative damage in subcutaneous white adipose tissue mitochondria in obese and type 2 diabetes subjects. Mol Cell Biochem 2015;399:95-103.

9. Obregon MJ. Adipose tissues and thyroid hormones. Front Physiol 2014;5:479.

10. Giammanco M, Di Liegro CM, Schiera G, Di Liegro I. Genomic and non-genomic mechanisms of action of 2 thyroid hormones and their catabolite 3,5-Diiodo-L-3 thyronine in mammals. Int J Mol Sci 2020;21,4140.

11. Moreno M, Lombardi A, Beneduce L, et al. Are the effects of $\mathrm{T} 3$ on resting metabolic rate in euthyroid rats entirely caused by T3 itself? Endocrinology 2002;143:504-10.

12. Goglia F. The effects of 3,5-diiodothyronine on energy balance. Front Physiol 2015;5:528.

13. Lanni A, Moreno M, Lombardi A, et al. 3,5-Diiodo-L-thyronine powerfully reduces adiposity in rats by increasing the burning of fats. FASEB J 2005;19:1552-4.

14. De Lange P, Cioffi F, Senese R, et al. Non-thyrotoxic prevention of diet-induced insulin resistance by 3,5-Diiodo-LThyronine in rats. Diabetes 2011;60:2730-9.

15. Silvestri E, Senese R, Cioffi F. et al. 3,5-Diiodo-L-Thyronine exerts metabolically favorable effects on visceral adipose tissue of rats receiving a high-fat diet. Nutrients 2019, 11, 278

16. Lehmphul I, Brabant G, Wallaschofski H, et al. Detection of 3,5-diiodothyronine in sera of patients with altered thyroid status using a new monoclonal antibody-based chemiluminescence immunoassay. Thyroid 2014;24:1350-60.

17. Pietzner M, Lehmphul I, Friedrich N, et al. Translating pharmacological findings from hypothyroid rodents to euthyroid 
humans: Is there a functional role of endogenous 3,5-T2? Thyroid 2015;25:188-97.

18. Pietzner M, Homuth $\mathrm{G}$, Budde $\mathrm{K}$, et al. Urine metabolomics by (1)H-NMR spectroscopy indicates associations between serum 3,5-T2 concentrations and intermediary metabolism in euthyroid humans. Eur Thyroid J 2015;4:92-100.

19. Dietrich JW, Müller P, Schiedat F, et al. nonthyroidal illness syndrome in cardiac illness involves elevated concentrations of 3,5-Diiodothyronine and correlates with atrial remodeling. Eur Thyroid J 2015;4:129-37.

20. Giammanco M, Aiello S, Casuccio A, et al. Effects of 3,5diiodo-L-thyronine on the liver of high fat diet fed rats. J Biol Res - Boll Soc Ital Biol Sper 2016;89:5667.

21. Padron AS, Neto RA, Pantaleão TU, et al. Administration of 3,5-diiodothyronine (3,5-T2) causes central hypothyroidism and stimulates thyroid-sensitive tissues. J Endocrinol 2014;221:415-27.

22. Vatner DF, Snikeris J, Popov V, et al. 3,5 Diiodo-L-Thyronine (T2) does not prevent hepatic steatosis or insulin resistance in fat-fed sprague dawley rats. PLoS ONE 2015,10,e0140837.

23. da Silva TS, Filgueira C, Sieglaff DH, et al. 3,5-diiodothyronine $(3,5-\mathrm{T} 2)$ reduces blood glucose independently of insulin sensitization in obese mice. Acta Physiol (Oxf.) 2017:220: 238-50.

24. Lietzow J, Golchert J, Homuth G, et al. 3,5-T2 alters murine genes relevant for xenobiotic, steroid, and thyroid hormone metabolism. J Mol Endocrinol 2016;56:311-23.

25. Grani G, Cooper DS. Levothyroxine treatment increases mortality in patients with heart failure. Clin Thyroidol 2019;31: 95-8.

26. Hulbert AJ. Thyroid hormones and their effects: a new perspective. Biol Rev 2000;75:519-631.

27. Moreno M, Lanni A, Lombardi A, et al. Control of energy metabolism by iodothyronines. J Endocrinol Investigat 2001;24:897-913.

28. Horst C, Rokos H and Seitz HJ. Rapid stimulation of oxygen consumption by 3,5-diiodo-L-thyronine. Biochem J 1989;261:945-50.

29. Lanni A, Moreno M, Cioffi M, Goglia F. Effect of 3,3'diiodothyronine and 3,5-diiodothyronine on rat liver oxidative capacity. Molec Cell Endocrinol 1992;86:143-8.

30. O'Reilly I, Murphy MP. Studies on the rapid stimulation of mitochondrial respiration by thyroid hormones. Acta Endocrinol 1992;127:142-6.

31. Tata JR. Inhibition of the biological action of thyroid hormones by actinomycin D and puromycin. Nature 1963;197: 1167-8.

32. Tata, JR, Ernster L and Lindberg O. Control of basal metabolic rate by thyroid hormone and cellular function. Nature 1962; 198:1058-60.

33. Tata JR, Ernster L, Lindberg O, et al. The action of thyroid hormone at the cell level. Biochem 1963;86:408-28.

34. Leonard JL, Koehrle J. in Werner \& Ingbar's. The thyroid: a fundamental and clinical text (Braverman LE and Utiger RD; eds.) Philadelphia: Lippincott, Williams \& Wilkins; 2002. pp.136-73.

35. Lanni A, Moreno M, Lombardi A, Goglia F. Calorigen effect of diiodothyronines in the rat. J Physiol 1996;494:831-7.

36. Moreno M, Lanni A, Lombardi A, Goglia F. How the thyroid controls metabolism in the rat: different roles for triiodothyronine and diiodothyronines. J Physiol 1997;505:529-53.

37. Lanni A, Moreno M, Lombardi A, Goglia F. 3,5-diiodo-L-thyronine and 3,5,3'-triiodo-L-thyronine both improve the cold tolerance of hypothyroid rats, but possibly via different mechanisms. Pflugers Arch 1998;436:407-14.

38. Cimmino M, Mion F, Goglia F, et al. Demostration of in vivo metabolic effects of 3,5-diiodothyronine. J Endocrinol 1996;149: 319-25.

39. Goglia F, Lanni A, Barth J, Kadenbach B. Interaction of diiodothyronines with isolated cytochrome c oxidase. FEBS Lett 1994;346:295-8.

40. Moreno M, Silvestri E, Lombardi A, et al. Identification of 3,5-diiodo-L-thyronine-binding proteins in rat liver cytosol by photoaffinity labeling. Endocrinology 2003;144:2297-303.

41. Goglia F, Lanni A, Horst C, et al. In vitro binding of 3,5-diiodo-L-thyronine to rat liver mitochondria. J Mol Endocrinol 1994;13:275-82.

42. Lanni A, Moreno M, Lombardi A, et al. Control of energy metabolism by iodothyronines. J Endocrinol Invest 2001;24: 897-913.

43. Arnold S, Goglia F, Kadenbach B. 3,5-Diiodothyronine binds to subunit $\mathrm{Va}$ of cytochrome-c oxidase and abolishes the allosteric inhibition of respiration by ATP. Eur J Biochem 1998;252:325-30.

44. Hummerich H, Soboll S. Rapid stimulation of calcium uptake into rat liver by L-tri-iodothyronine. Biochem J 1989;258:363-7.

45. Denton RM, McCormack JG. Ca2+ transport by mammalian mitochondria and its role in hormone action. Am J Physiol 1985;249:543-54.

46. Huang CJ, Geller HM, Green WL, Craeliu W. Acute effects of thyroid hormone analogs on sodium currents in neonatal rat myocytes. J Mol Cell Cardiol 1999;31:881-93.

47. Incerpi S, De Vito P, Luly P, et al. Short-term effects of thyroid hormones and 3,5-diiodothyronine on membrane transport systems in chick embryo hepatocytes. Endocrinology 2002;143:1660-8.

48. Ramsey JJ, Harper ME, Weindruch R. Restriction of energy intake, energy expenditure, and aging. Free Radic Biol Med 2000;29:946-68.

49. Velasco G, Geelen MJ, Gómez del Pulgar T, Guzmán M. Malonyl-CoA-independent acute control of hepatic carnitine palmitoyltransferase I activity. Role of $\mathrm{Ca} 2+/$ calmodulindependent protein kinase II and cytoskeletal components. J Biol Chem 1998;273:21497-504.

50. Velasco G, Geelen MJ, Guzmán M. Control of hepatic fatty acid oxidation by 5'-AMP-activated protein kinase involves a malonyl-CoA-dependent and a malonyl-CoA-independent mechanism. Arch Biochem Biophys 1997;337:169-75.

51. Porter RK, Brand MD. Body mass dependence of $\mathrm{H}+$ leak in mitochondria and its relevance to metabolic rate. Nature 1993;362:628-30.

52. Grasselli E, Voci A, Canesi L, et al. Non-receptor-mediated actions are responsible for the lipid-lowering effects of iodothyronines in Fat rat hepatoma cells. J Endocrinol 2011;210: 59-69.

53. Munoz A, Hoppner W, Sap J, et al. The chicken c-erbA alphaproduct induces expression of thyroid hormone-responsive genes in 3,5,3'-triiodothyronine receptor-deficient rat hepatoma cells. Mol Endocrinol 1990;4:312-20.

54. Izumo S, Mahdavi V. Thyroid hormone receptor alpha isoforms generated by alternative splicing differentially activate myosin HC gene transcription. Nature 1988;334:539-42.

55. Lazar MA. Thyroid hormone receptors: multiple forms, multiple possibilities. Endocr Rev 1993;14:184-93.

56. Weiss RE, Murata Y, Cua K, et al. Thyroid hormone action on 
liver, heart, and energy expenditure in thyroid hormone receptor beta-deficient mice. Endocrinology 1998;139:4945-52.

57. Ye L, Li YL, Mellström K, et al. Thyroid receptor ligands. 1. Agonist ligands selective for the thyroid receptor beta1. J Med Chem 2003;46:1580-8.

58. Flores-Morales A, Gullberg H, Fernandez L, et al. Patterns of liver gene expression governed by TRbeta. Mol Endocrinol 2002; 16:1257-68.

59. Cioffi F, Zambad SP, Chhipa L, et al. TRC150094, a novel functional analog $\mathrm{f}$ iodothyronines, reduces adiposity by increasing energy expenditure and fatty acid oxidation in rats receiving a high-fat diet. FASEB J 2010;24:3451-61.

60. Nobes CD, Brown GC, Olive PN, Brand MD. Non-ohmic proton conductance of the mitochondrial inner membrane in hepatocytes. J Biol Chem 1990;265:12903-9.

61. Ferrannini E, Barrett EJ, Bevilacqua S, De Fronzo RA. Effect of fatty acids on glucose production and utilization in man. $\mathrm{J}$ Clin Invest 1983;72:1737-47.

62. Vock C, Gleissner M, Klapper M, Döring F. Oleate regulates genes controlled by signaling pathways of mitogen activated protein kinase, insulin, and hypoxia. Nutr Res 2008;28:681-9.

63. Grasselli E, Voci A, Pesce C, et al. PAT protein mRNA expression in primary rat hepatocytes: Effects of exposure to fatty acids. Int J Mol Med 2010;25:505-12.

64. Motomura W, Inoue M, Ohtake T, et al. Up-regulation of ADRP in fatty liver in human and liver steatosis in mice fed with high fat diet. Biochem Biophys Res Commun 2006;340:1111-8.

65. Targett-Adams P, McElwee MJ, Ehrenborg E, et al. A PPAR response element regulates transcription of the gene for human adipose differentiation-related protein. Biochim Biophys Acta 2005;1728:95-104.

66. Londos C, Sztalryd C, Tansey JT, Kimmel AR. Role of PAT proteins in lipid metabolism. Biochimie 2005;87:45-9.

67. Goglia F, Moreno M, Lanni A. Action of thyroid hormones at the cellular level: the mitochondrial target. FEBS Letters 1999;452:115-20.

68. Yoon M. The role of PPARalpha in lipid metabolism and obesity: focusing on the effects of estrogen on PPARalpha actions. Pharmacol Res 2009;60:151-9.

69. Schadinger SE, Bucher NL, Schreiber BM, Farmer SR. PPAR gamma 2 regulates lipogenesis and lipid accumulation in steatotic hepatocytes. Am J Physiol Endocrinol Metab 2005;288:1195-205.

70. Gavrilova O, Haluzik M, Matsusue K, et al. Liver peroxisome proliferator-activated receptor gamma contributes to hepatic steatosis, triglyceride clearance, and regulation of body fat mass. J Biol Chem 2003;278:34268-76.

71. De Lange P, Lombardi A, Silvestri E, et al. Peroxisome proliferator-activated receptor delta: a conserved director of lipid homeostasis through regulation of the oxidative capacity of muscle. PPAR Res 2008:2008;172676.

72. Roberts LD, Hassall DG, Winegar DA, et al. Increased hepatic oxidative metabolism distinguishes the action of Peroxisome proliferator-activated receptor delta from Peroxisome proliferator-activated receptor gamma in the ob/ob mouse. Genome Med 2009;1:115.

73. Wang YX, Lee $\mathrm{CH}$, Tiep S, et al. Peroxisome-proliferatoractivated receptor delta activates fat metabolism to prevent obesity. Cell 2003;113:159-70.

74. Nagasawa T, Inada Y, Nakano S, et al. Effects of bezafibrate, PPAR pan-agonist, and GW501516, PPARdelta agonist, on development of steatohepatitis in mice fed a methionine and choline-deficient diet. Eur J Pharmacol 2006;536:182-91.

75. Grasselli E, Voci A, Canesi L, et al. Direct effects of iodothyronines on excess fat storage in rat hepatocytes. J Hepatol 2011;54:1230-6.

76. Younossi ZM, Stepanova M, Negro F, et al. Nonalcoholic fatty liver disease in lean individuals in the United States. Med 2012;91:319-27.

77. Hribal ML, Procopio T, Petta S, et al. Insulin-Like Growth Factor-I, Inflammatory Proteins, and Fibrosis in Subjects With Nonalcoholic Fatty Liver Disease. J Clin Endocrinol Metab 2013;98:304-8.

78. Mangiullo R, Gnoni A, Damiano F, et al. 3,5-diiodo-L-thyronine upregulates rat-liver mitochondrial FoF1-ATP synthase by GA-binding protein/nuclear respiratory factor-2. Biochim Biophys Acta 2010;1797:233-40.

79. Sanyal AJ, Campbell-Sargent C, Mirshahi F, et al. Nonalcoholic steatohepatitis: association of insulin resistance and mitochondrial abnormalities. Gastroenterology 2001;120:1183-92.

80. Chalasani N, Gorski JC, Asghar MS, et al. Hepatic cytochrome P450 2E1 activity in nondiabetic patients with nonalcoholic steatohepatitis. Hepatology 2003;37:544-50.

81. Brady LJ, Brady PS, Romsos DR, Hoppel CL. Elevated hepatic mitochondrial and peroxisomal oxidative capacities in fed and starved adult obese (ob/ob) mice. Biochem J 1985;231:439-44.

82. Rousset S, Alves-Guerra MC, Mozo J, et al. The biology of mitochondrial uncoupling proteins. Diabetes 2004;53:S130-5.

83. Krauss S, Zhang CY, Lowell BB. The mitochondrial uncoupling-protein homologues. Nat Rev Mol Cell Biol 2005;6: 248-61.

84. Kadenbach B, Hüttemann M, Arnold S, Lee I, Bender E. Mitochondrial energy metabolism is regulated via nuclearcoded subunits of cytochrome c oxidase. Free Radic Biol Med 2000;29:211-21.

85. Kadenbach B. Intrinsic and extrinsic uncoupling of oxidative phosphorylation. Biochim Biophys Acta 2003;1604:77-94.

86. Fleury C, Sanchis D. The mitochondrial uncoupling protein2: current status; Biochem Cell Biol 1999;31:1261-78.

87. Mollica MP, Lionetti L, Moreno M, et al. 3,5-diiodo-L-thyronine, by modulating mithocondrial function, reverses hepatic fat accumulation in rats fed a higt-fat diet. J Hepatol 2009;51: 363-70.

88. Jezek P. Possible physiological roles of mitochondrial uncoupling proteins - UCPn. Int J Biochem Cell Biol 2002;34: 1190-206.

89. Kasai H, Okada Y, Nishimura S, et al. Formation of 8-hydroxydeoxyguanosine in liver DNA of rats following long-term exposure to a peroxisome proliferator. Cancer Res 1989;49: 2603-5.

90. Yang S, Zhu H, Li Y, et al. Mitochondrial adaptations to obesity-related oxidant stress. Arch Biochem Biophys 2000;378: 259-68.

91. Grasselli E, Canesi L, Voci A, et al. Effects of 3,5-Diiodo-LThyronine Administration on the Liver of High Fat Diet-Fed Rats. Exp Biol Med 2008;233:549-57.

92. Nobili V, Pastore A, Gaeta LM, et al. Glutathione metabolism and antioxidant enzymes in patients affected by nonalcoholic steatohepatitis. Clin Chim Acta 2005;355:105-11.

93. Vergani L, Lanza C, Borghi C, et al. Effects of growth hormone and cadmium on the transcription regulation of two metallothionein isoforms. Mol Cell Endocrinol 2007;263:29-37.

94. Vergani L, Grattarola M, Borghi C, et al. Fish and molluscan metallothioneins. FEBS J 2005;272:6014-23. 
95. Hidalgo J, Campmany L, Borras M, et al. Metallothionein response to stress in rats: role in free radical scavenging. Am J Physiol 1988;255:E518-24.

96. Zhou Z, Sun X, James Kang Y. Metallothionein protection against alcoholic liver injury through inhibition of oxidative stress. Exp Biol Med 2002;227:214-22.

97. Ye B, Maret W, Vallee BL. Zinc metallothionein imported into liver mitochondria modulates respiration. Proc Natl Acad Sci USA 2001;98:2317-22.

98. Beattie JH, Wood AM, Newman AM, et al. Obesity and hyperleptinemia in metallothionein (-I and -II) null mice. Proc Natl Acad Sci U S A. 1998 ;95:358-63.

99. Krezel A, Maret W. Different redox states of metallothionein/ thionein in biological tissue. Biochem J 2007;402:551-8.

100. Reddy JK. Nonalcoholic steatosis and steatohepatitis. III. Peroxisomal beta-oxidation, PPARalpha and steatohepatitis. Am J Physiol Gastrointest Liver Physiol 2001;281:1333-9.

101. Reddy JK, Rao MS. Lipid metabolism and liver inflammation. II. Fatty liver disease and fatty acid oxidation. Am J Physiol Gastrointest Liver Physiol 2006;290:852-8.

102. Akbiyik F, Cinar K, Demirpence E, et al. Ligand-induced expression of peroxisome proliferator-activated receptor alpha and activation of fatty acid oxidation enzymes in fatty liver. Eur J Clin Invest 2004;34:429-35.

103. Patsouris D, Reddy JK, Müller M, Kersten S. Peroxisome proliferator-activated receptor alpha mediates the effects of highfat diet on hepatic gene expression. Endocrinology 2006;147: 1508-16.

104. Redonnet A, Groubet R, Noël-Suberville C, et al. Exposure to an obesity-inducing diet early affects the pattern of expression of peroxisome proliferator, retinoic acid, and triiodothyronine nuclear receptors in the rat. Metabolism 2001;50:1161-7.

105. Hsu SC, Huang CJ. Changes in liver PPAR alpha mRNA expression in response to two levels of high-safflower-oil diets correlate with changes in adiposity and serum leptin in rats and mice. J Nutr Biochem 2007;18:86-96.

106. Nakamuta M, Kohjima M, Morizono S, et al. Evaluation of fatty acid metabolism-related gene expression in nonalcoholic fatty liver disease. Int J Mol Med 2005;16:631-5.

107. Bradbury MW. Lipid metabolism and liver infiammation. Hepatic fatty acid uptake: possible role in steatosis. Am J Physiol Gastrointest Liver Physiol 2006; 290:194-8.

108. Cherian MG, Kang YJ. Metallothionin and liver cell regeneration. Exp Biol Med 2006;231:138-44.

109. Oliver JR, Jiang S, Cherian MG. Augmented hepatic injury followed by impaired regeneration in metallothionein-I/II knockout mice after treatment with thioacetamide. Toxicol Appl Pharmacol 2006;210:190-9.

110. Palmiter RD. The elusive function of metallothioneins. Proc Natl Acad Sci USA 1998;95:8428-30.

111. Winge DR, Nielson KB, Zeikus RD, Gray WR. Structural characterization of the isoforms of neonatal and adult rat liver metallothionein. J Biol Chem 1984;259:11419-25.

112. Do MS, Nam SY, Hong SE, et al. Metallothionein gene expression in human adipose tissue from lean and obese subjects. Horm Metab Res 2002;34:348-51.

113. Andrews GK. Regulation of metallothionein gene expression by oxidative stress and metal ions. Biochem Pharmacol 2000;59:95-104.

114. Haq F, Mahoney M, Koropatnick J. Signaling events for metallothionein induction. Mutat Res 2003;533:211-26.

115. Kumari MV, Hiramatsu M, Ebadi M. Free radical scavenging actions of metallothionein isoforms I and II. Free Radic Res 1998;29:93-101.

116. Grover GJ, Mellstrom K, Malm J. Development of the Thyroid Hormone Receptor $\beta$-Subtype Agonist KB-141 : A Strategy for Body Weight Reduction and Lipid Lowering with Minimal Cardiac Side Effects. Cardiovasc Drug Rev 2005;23:133-48.

117. Antonelli A, Fallahi P, Ferrari SM. 3,5-diiodo-L-thyronine increases resting metabolic rate and reduces body weight without undesirable side effects. J Biol Regul Homeost Agents 2011, 25:655-660. 